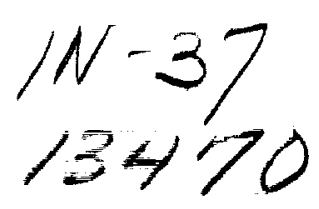

NASA

Technical Memorandum 104388

AVSCOM

Technical Report 91-C-015

$$
p, 14
$$

\title{
Effects of Rim Thickness on Spur Gear Bending Stress
}

G.D. Bibel, S.K. Reddy, and M. Savage

University of Akron

Akron, Ohio

and

R.F. Handschuh

Propulsion Directorate

U.S. Army Aviation Systems Command

Lewis Research Center

Cleveland, Ohio

Prepared for the

27th Joint Propulsion Conference

cosponsored by the AIAA, SAE, and ASME

Sacramento, California, June 24-26, 1991 


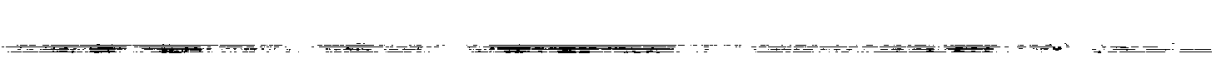




\title{
EFFECTS OF RIM THICKNESS ON SPUR GEAR BENDING STRESS
}

\author{
G.D. Bibel, S.K. Reddy, and M. Savage \\ University of Akron \\ Akron, Ohio 44325
}

and

R.F. Handschuh

Propulsion Directorate

U.S. Army Aviation systems Command

Lewis Research Center

Cleveland, Ohio 44135

\section{Abstract}

Thin rim gears find application in high-power, lightweight aircraft transmissions. Bending stresses in thin rim spur gear tooth fillets and root areas differ from the stresses in solid gears due to rim deformations. Rim thickness is a significant design parameter for these gears. To study this parameter, a finite element analysis was conducted on a segment of a thin rim gear. The rim thickness was varied and the location and magnitude of the maximum bending stresses reported. Design limits are discussed and compared with the results of other researchers.

\section{Nomenclature}

A point at the end of the line of action at the gear base circle

B highest point of single tooth contact on pinion tooth

c point at the intersection of the gear addendum circle and the line of action

$D$ point at the end of the line of action at the pinion base circle

F force (1b)

h tooth height (in.)

$M$ support moment about edge centrode (1b-in.)

n cuter surface normal unit vector
$\mathrm{N}$ number of teeth

o gear or pinion center

$\mathrm{p}_{\mathrm{b}}$ base pitch (in.)

$P_{d}$ diametral pitch $\left(i n .^{-1}\right)$

$\mathrm{R}$ pitch radius (in.)

s tooth surface location from left edge (in.)

$t$ rim depth (in.)

u line of action location of gear addendum circle (in.)

$v_{1 j}$ relative velocity between cutter and gear blank (in./sec)

$\beta \quad$ rim backup ratio

$\gamma$ rim location angle (deg)

$\theta$ roll angle (deg)

$\sigma \quad$ maximum compressive stress (ksi)

$\sigma_{I} \quad$ rim surface stress (ksi)

$\sigma_{\mathrm{R}}$ maximum stress range (ksi)

$\sigma_{t}$ tooth surface stress (ksi)

$\sigma_{T}$ maximum tensile stress (ksi)

$\sigma_{\text {TO }}$ base maximum tensile stress (ksi)

$\phi$ pressure angle (deg) 


\section{Subscripts}

ag gear addendum
B highest point of single tooth
contact
gear
i node count index
$j \quad$ node index
$1 \quad$ left end
$p \quad$ pinion
$x \quad$ right end
$x \quad$ horizontal
$y \quad$ vertical

Introduction

one major cause of gear failure is fracture at the base of the gear tooth due to bending fatigue. Design models for this mode of failure use a parabolic beam with stress concentration correction. 1 The bending strength is influenced by: the gear size, described by the diametral pitch; the shape of the tooth, described by the number of teeth on the gear; the highest location of the full load, described by the number of teeth on the mating gear; and the fillet geometry of the gear tooth. The present AGMA design model treats these factors directly and by extrapolating limited experimental data for the stress concentration correction.

For thin rim gears, the thickness of the rim is another gignificant factor which influences the bending strength of the gear. Rim deflections increase the bending stresses in the tooth fillet and root areas. Therefore in aircraft applications, the rim thickness and allowable stress are optimized to achieve light weight.

Wilcox and coleman ${ }^{2}$ applied the finite element method to analyze the bending stresses in a gear tooth of a solid gear and demonstrated good agreement with photoelastic stress measurements.

For thin rim gearing, Drago et al. ${ }^{3,4}$ studied rimmed gear stresses experimentally with strain gages and photoelastic models and analytically with two and three-dimensional finite element models. Their studies report a nearly constant bending stress as the rim thickness decreases and a sudden increase in bending stress below a certain rim thickness.

Analytical studies have been conducted on thin rim gear stresses with finite elements by several researchers. oda et al. ${ }^{5}$ studied a single tooth model of a thin rim spur gear using a five tooth segment fixed at its sides. They used strain gages to verify their results. Arai et al. " studied a spoked thin rim gear with four teeth in the free rim arc between spokes. Chang et al. applied a two-dimensional finite element grid to a single thin rim tooth with fixed constraints at the tooth sides to demonstrate the stress distribution in the tooth. Chong et al. ${ }^{8}$ used twodimensional triangular finite elements and a rack model to study the effects of the rim on the bending stress in the fillet. Their rack model had statically determinate beam supports on segments of different lengths. Von Eiff et al. ${ }^{9}$ used a finite element model of a three tooth segment for both external and internal gears to study the maximum bending stresses at the root of the central tooth. Gulliot and Tordion ${ }^{10}$ analyzed the problem of a thin rim on a support hub using the finite element method.

All of these studies report a nearly constant tensile bending stress as the rim thickness decreases to a value near the tooth depth. The tensile root stress increases rapidly with further reductions of rim thickness. However, each study reported a different transition rim thickness value. These studies also differed in the rim support geometry and the number of teeth on the gear. The ring 
flexibility of the rim influences both the tooth stiffness ${ }^{11}$ and the location and magnitude of the maximum bending stress in a thin rim gear. Thus, the support constraints affect the maximum bending stress.

Herein, a five tooth segment of a 25 tooth gear in mesh with a 50 tooth gear is studied. A rack tip generated trochoid fillet ${ }^{12}$ is at the base of the involute to describe accurately the structural geometry of the tooth. The rim depth to tooth height ratio is varied to study its effects on the bending tensile and compressive stresses at the base of the loaded tooth and to investigate the support loading and its influence on the bending stresses.

\section{Gear Tooth Geometry}

The pinion studied had a diametral pitch of 10, 25 teeth, and a nominal pressure angle of $20^{\circ}$. The pinion and mating 50 tooth gear had standard full depth teeth with addendum ratios of 1.0 and dedendum ratios of 1.35. The rack form cutter tip had a sharp corner and the face width of the gears was 0.625 in. A 500 lb load acted between the gears along the line of action corresponding to a pinion torque of $587.3 \mathrm{lb}-$ in. with no dynamic loading factor. Table I summarizes the geometry of the gear mesh.

Development of the finite element model begins with data describing the outline of a single tooth and its fillets from the center of the tooth space on one side to the center of the tooth space on the other side. Several different curves make up the tooth outline: concentric circular arcs at the outside tooth tip and the bottom tooth space lands, involutes on the two sides of the tooth, and trochoides between the involutes and the bottom lands at the base of the tooth. Figure 1 identifies these curves on the tooth outline. The tooth side involutes, fillet trochoides, and bottom lands are shaped to model a gear cut with a rack form cutter.
Coordinates for the surface profile of the tooth come from a kinematic analysis of the cutting process. ${ }^{12}$ Both the rack form cutter and the resulting gear surface are tangent to each other at the cutting points, which generate the gear shape from the rack shape. At the cutting points, the rack form and gear blank have a relative velocity which acts in the tangential cutting direction in the plane of the gears. One can find the coordinates of the cut points on the gear as the locus of coincident points for which the relative velocity is tangent to the rack form surface. The dot product of the surface normal to the rack form, $n$, with the relative velocity between the tool and blank, $v_{1 j}$, is zero at these points:

$$
\mathbf{n} \cdot \mathbf{v}_{i j}=0
$$

The involute is generated by points on the side of the rack form, the gear tooth fillet is generated by the tip of the rack form, and the bottom land is generated by the top surface of the rack form tooth.

The load on the central tooth of the finite element model, which produces the largest bending stress, is the full load acting at the highest point of single tooth contact. 1,3,4,13 Figure 2 shows the gears in mesh with the pinion tooth loaded at the highest point of single tooth contact. This location, point B, is one base pitch above the addendum circle of the mating gear, point $c$, on the line of action. The distance from the addendum circle on the mating gear to the base circle of the pinion, point $D$, along the line of action, called $u$ is:

$$
\begin{aligned}
u & =\overline{A D}-\overline{A C} \\
& =\left(R_{p}+R_{g}\right) \sin \phi-\left(R_{a g}^{2}-R_{g}^{2} \cos ^{2} \phi\right)^{1 / 2}
\end{aligned}
$$

where $R$ is the pitch radius of the pinion, $R_{g}$ is the pitch radius of the mating gear, and $R_{a g}$ is the addendum or 
outside radius of the mating gear. The roll angle, $\theta_{1}$, to the highest point of single tooth loading on the pinion is:

$$
\theta_{B}=\frac{u+p_{b}}{R_{p} \cos \phi}
$$

where $p_{b}$ is the base pitch of the gear mesh. The base pitch is related to: the pitch radius of the pinion, $R_{p}$; the nominal pressure angle, $\phi ;$ and the number of teeth on the pinion, $\mathrm{N}_{\mathrm{p}}$; by

$$
\mathrm{p}_{\mathrm{b}}=\frac{2 \pi \mathrm{R}_{\mathrm{p}}}{N_{\mathrm{p}}} \cos \phi
$$

This roll angle, $\theta_{1}$, determines the pressure angle at the highest point of single tooth contact, $\phi_{B^{\prime}}$ and the radius to that point on the tooth surface, $R_{B}$. The pressure angle between the line of action and the circumferential direction at the highest point of single tooth contact, $\phi_{\mathrm{B}}$, is:

$$
\phi_{B}=\tan ^{-1} \theta_{B}
$$

The radius to that point is:

$$
R_{B}=\frac{R_{P} \cos \phi}{\cos \phi_{B}}
$$

With the appropriate rotations, this slope and radius locates the direction and point of application of the gear mesh force on the central tooth in the five tooth segment model.

\section{Finite Element Model}

A model congisting of a five tooth section of a 25 tooth pinion was developed with the general purpose finite element program. ${ }^{14}$ Figure 3 shows the finite element grid for the five tooth gear segment. Successive reflections of the coordinates for the initial tooth generated a segment of five equally spaced, identical teeth. The inside edge of the model is a constant radius arc which has different radii for the different rim thickness ratio cases. Both the tooth surface and the inside rim surface are unconstrained. At the sides, two radial 1 ines, at $\pm 36^{\circ}$ from the segment center, complete the outline of the model.

Rim support was modeled by constraining the radial side cuts in the gear rim at all node points to have zero displacement. The load of $500 \mathrm{lb}$ was applied at the highest point of single tooth contact on the central tooth in the direction of the line of action. To apply the load at a node, the grid had to have a node point at or near this loading point.

A six node iso-parametric planestress triangular element was used to build the finite element models inside the frameworks described above. This element has a quadratic displacement function and is well-suited for analyzing irregular shapes. A lattice of three integration points is used with the numerical (Gaussian) integration procedure. Each node in the element has 2 degrees of freedom - translations in the $x$ and $y$ directions. ${ }^{14}$ The plane stress option with unit thickness was used and scaled to the actual model thickness of 0.625 in. As can be seen in Figs. 3 and 4 , a fine mesh was used in the root and fillet areas of all teeth. Figure 4 shows the left side of the central tooth which had an even finer element spacing of about 0.006 in. on both sides to provide more accurate information on the stress in these regions. The complete model has 1308 elements, 2777 nodes, and 5554 degrees of freedom.

To evaluate segments with different rim thicknesses, the lower elements in the rim below the tooth and a minimum rim thickness were placed in eight concentric rings of equal thickness. Nine separate models were obtained by removing successive rings of inside elements. This varied the backup ratio of rim thickness to full tooth height from a maximum value of 2.55 down to a minimum value of 0.45 . 


\section{Bending Stresses}

To aid in visualization, the extrapolated nodal stresses along the top and bottom surfaces of the gear tooth segment model were plotted versus position on the segment. These stresses were studied for the case of full load at the highest point of single tooth contact and for two other cases of shared loading at the tooth tip which produced lower stresses. The cases with lower bending stresses ${ }^{13}$ are not presented here.

Figure 5 shows the five tooth segment with some labeling and both the thinnest and thickest rims. Circumferential locations are labeled Tl through T5, R1 through R4, and $E 1$ and $E 2$ to represent: the middle of the tooth tops at $T 1$ to $T 5$, the middle of the tooth spaces at $R 1$ to $R 4$, and the left and right sides of the segment at $\mathrm{E} I$ and $\mathrm{E} 2$.

The full tooth height is labeled $h$, and Fig. 5 shows both the minimum rim, $t_{\text {min' }}$ and maximum rim, $t_{\text {max }}$ cases superimposed on each other. The backup ratio, $\beta$, of rim thickness to tooth height is defined as:

$$
\beta=\frac{t}{h}
$$

To locate the stresses along the teeth, the surface distance from the left edge of the segment, $E 1$, to node $j, \mathbf{s}_{j^{\prime}}$ was calculated as:

$$
\mathbf{s}_{j}=\sum_{i=1}^{j}\left(\Delta x_{i}^{2}+\Delta y_{i}^{2}\right)^{1 / 2}
$$

where $\Delta x_{1}$ is the incremental distance between surface nodes in the $x$ direction at node $i$ and $\Delta y_{1}$ is the incremental distance between surface nodes in the $y$ direction at node $i$.

Figure 6 contains plots of the principal stress in the plane of the tooth surface, $\sigma_{t}$, as a function of the distance, $s$, from the left edge of the segment for the largest and smallest backup ratios. The dashed curve is for the largest ratio of $\beta=2.55$ while the solid curve is for the smallest backup ratio of $\beta=0.45$.

In these plots, one can see high bending tensile and compressive stresses in the roots $R 2$ and $R 3$, immediately before and after the loaded tooth. Smaller bending tensile and compressive stresses are present in the roots $R I$ and R4 which are one tooth further away from the loaded tooth. Even smaller tensile and compressive stresses are present at $E 1$ and $E 2$ in the roots at the segment boundaries where the fixed constraints are present.

Figure 7 has similar plots of the surface normal stress on the rim bottom surface, $\sigma_{g^{\prime}}$ for the same backup ratios of 2.55 and 0.45 . These plots are drawn versus a central angle, $\gamma$, measured clockwise from the left edge of the segment. An angular measure of location, $\gamma$, provides similar direct comparisons among these plots for the different backup ratios. The labeling points $T 1$ through T5 and RI through R4 locate the teeth in the plots and match the rim bottom stresses to the tooth surface stresses.

The surface stresses in the rim bottom, $\sigma_{r}$, are ring flexing stresses. They also combine with the top surface stress, $\sigma_{t}$, to describe partially the support loading which is statically indeterminate. In all cases, larger surfaces stresses at the right segment edge indicate larger support reactions at the right than at the left. The compressive load path to the loaded tooth in the arch is stiffer than the tensile load path behind the tooth due to the orientation of the load. However, integration of the fixed boundary stresses is necessary to determine the full support normal, shear and moment reactions.

Figure 8 is a force diagram of the thinnest rim segment with its applied and support loading. As indicated by the size of the arrows and the magnitudes of the edge stresses in Figs. 6 and 7 , the primary support for the load is from the right side, with a shear load dominating 
the left side reactions. Both sides have small support moments in this thin rim case which are shown as slight displacements of the support reactions from the rim section centers. Table II lists the left and right support reactions for the nine rim thickness cases studied.

The influence of rim thickness on the bending stresses is summarized in Fig. 9. The figure plots the maximum tensile, $\sigma_{T^{\prime}}$ and compressive, $\sigma_{C^{\prime}}$ stresses at the base of the loaded tooth, and the maximum stress range, $\sigma_{R^{\prime}}$ in this region as a function of the backup ratio, $\beta$. The maximum stress range, $\sigma_{R^{\prime}}$ is twice the maximum alternating stress in the tooth root. Since only one tooth was loaded in this model, the stress range was calculated as the difference between the stresses in the root at one side of the loaded tooth and those at similar points on the other side of the loaded tooth one full tooth surface distance away. All of these stresses are divided by the maximum tensile tooth surface stress for the thickest rim case, $\sigma_{\text {To }}$. This base stress, $\sigma_{\text {To' }}$ is close to the maximum tensile bending stress for a solid gear. Ratios to this stress, $\sigma_{\text {TO' }}$ give the relative magnitudes of the maximum thin rim surface stresses.

The maximum tensile stress acts higher on the tooth than the maximum compressive stress or the maximum stress variation act. The plot shows a small reduction in the tensile stress as the backup ratio decreases to a value of about 0.7. Below this value, the tensile stress rises with further reductions in rim thickness.

It should be noted that both the compressive and the alternating stresses, which act lower on the tooth, rise as the rim thickness decreases. However, these stresses only begin to rise appreciably at a backup ratio of 1.3 or less.

The reduction in maximum tensile stress at the root of the tooth with the reduction in backup ratio is surprising. However, both the tensile and compressive tooth bending stresses are influenced by a rim flexing stress which increases as the rim thickness decreases. This compressive stress, which acts on the top surface of the segment, is caused by the radial component. of the tooth load. Thus compressive stress is superimposed on both the tensile and compressive tooth bending stresses by the rim flexibility. These additional compressive stresses are responsible for the decrease in maximum tensile tooth bending stress with a decrease in rim thickness. The effect also causes the maximum compressive bending stresses on the tooth root to steadily increase with decreasing backup ratio.

\section{Stress Comparisons}

The influence of the rim on the tensile, compressive and alternating stresses noted in this work has been observed by others. 3-10 In the other studies on rim thickness effects, only Drago ${ }^{3,4}$ applies the load at the highest point of single tooth contact on the pinion. This is the loading condition which produces the highest bending stresses in the tooth and the rim. The cases of shared load as a pinion tooth enters and leaves the loaded region were studied in this work also. ${ }^{13}$ on entering the mesh, a pinion tooth sees load near its base from the tip of the gear tooth, while its preceding tooth sees load at its highest point of single tooth contact. On leaving the mesh, a pinion tooth sees load at its tip, while its following tooth sees load at its lowest point of single tooth contact. The loads were assumed to be shared equally between the two teeth. Both additional cases produced lower bending stresses in this study.

All other studies ${ }^{5-10}$ placed the full load at the tip of the pinion tooth. Although the full load does not act at the pinion tooth tip in practice, the results of the studies agree in principal with the results presented here.

Other differences between the studies include the number of teeth on the loaded gear and the elastic support for the loaded gear segment. Table III 
summarizes these differences and presents the rim backup ratio of each study for which the thin rim gear bending stresses increase over those for a similar solid gear. A brief description of each model is included in the table. The models were both experimental and analytical. Both strain gage measurements and photoelastic models provided validation for the numerical finite element studies. Support configurations included: fixed sides for short rim segments, beam supports with axial expansion allowed, hub support under the rim, and spoke support at the segment edges. In comparing the studies, the dominant influence appears to be the stiffness of the rim support configuration. Stiffer support geometries permit thinner rims without increasing the rim bending stresses.

Different rim designs will behave differently as the different studies suggest. The objective of these studies was to find the limit at which thin rim gear bending stresses increase over those of a solid gear. In this light, a backup ratio of 1.2 as suggested by the AGMA design code ${ }^{1}$ appears to be prudent. In future work, the ring size, gear loading, and support geometry differences produced by varying the number of teeth should be investigated to obtain design modification factors for thin rim designs. These studies should be conducted on a model which properly provides the minimum practical elastic support for the thin rim gear.

\section{Summary}

A study was conducted on the bending stresses in a thin rim spur pinion with 25 teeth in mesh with a 50 tooth gear. The study uged a finite element model of a five tooth segment with the central tooth loaded at the highest point of single tooth contact and the edges rigidly supported. At backup ratios above 1.3 , no appreciable change in the maximum tensile, compressive or alternating bending stresses at the base of the loaded gear tooth over those for a solid gear were observed.
The tensile stresses decreased slightly with decreases in backup ratio until a value of 0.7 was reached. At this value the maximum tensile bending stress increased. with further decreases in the rim backup ratio.

Both the maximum compressive and the maximum alternating bending stresses in the tooth root increased with decreases in the rim backup ratio. These increases were not significant until the backup ratio dropped to values below 1.3 .

The general trends of increasing tensile and compressive bending stresses with decreasing backup ratio agree with the published literature. Differences in the reported backup ratio at which the increases become measurable were seen to depend primarily on rim support geometry. The stiffer the rim support, the lower is the backup ratio at which the stresses increase over those of a similar solid gear.

\section{References}

1. "Fundamental Rating Factors and Calculation Methods for Involute spur and Helical Gear Teeth," ANSI/AGMA 2001-B88, American Gear Manufacturers Association, Arlington, VA, 1988 .

2. Wilcox, L. and coleman, W., "Application of Finite Elements to the Analysis of Gear Tooth Stresses," Journal of Engineering for Industry, Vol. 95, No. 4, Dec. 1973, pp. 1139-1148.

3. Drago, R.J., Brown, F.W., and Faust, H.S., "Recent Advances in the Evaluation of Stresses in Lightweight, High-Speed, Heavily Loaded Gearing," Reliability, Stress Analysis and Failure Prevention Methods in Mechanical Design, W.D. Milestone, ed., ASME, 1980, pp. 225-235. 
4. Drago, R.J. and Lutthans, R.V., "Combined Effects of Rim Thickness and Pitch Diameter on Spur Gear Tooth Stresses," Journal of the American Helicopter Society, Vol. 28, No. 3, July 1983, pp. 13-19.

5. Oda, S., Nagamura, K., and Aoki, K., "Stress Analysis by Thin Rim Spur Gears by Finite Element Method," Bulletin of the Japanese society of Mechanical Engineers, Vol. 24, No. 193, 1981, pp. 1273-1280.

6. Arai, N., Harada, S., and Aida, T., "Research on Bending Strength Properties of Spur Gears with a Thin Rim," Bulletin of the Japanese Society of Mechanical Engineers, Vol. 24, No. 195, 1981, pp. 1642-1650.

7. Chang, S.H., Huston, R.L., and Coy, J.J., "A Finite Element Stress Analysis of Spur Gears Including Fillet Radii and Rim Thickness Effects," Journal of Mechanisms, Transmissions and Automation in Design, Vol. 105, No. 3, Sept. 1983, pp. 327-330.

8. Chong, T.H., and Kubo, A., "Simple Stress Formulas for a Thin-Rimmed Spur Gear," Journal of Mechanisms, Transmissions and Automation in Design, Vol. 107, No. 3, Sept. 1985, pp. 406-423.
9. von Eiff, H., Hirschmann, K.H. and Lechner, G., "Influence of Gear Tooth Geometry on Tooth Stress of External and Internal Gears," Journal of Mechanical Design, Vol. 112, No. 4, 1990, pp. 575-583.

10. Gulliot, M. and Tordion, G.V., "Stress Analysis of Thin Rim Spur Gears by Finite Element Method," 1989 International Power Transmission and Gearing Conference, Vol. 1 , ASME, New York, 1989, pp. 167-172.

11. Savage, M., Caldwell, R.J., Wisor, G.D., and Lewicki, D.G., "Gear Mesh Compliance Modeling," NASA TM-88843, 1986.

12. Hefeng, B., Savage, M., and Knorr, R.J., "Computer Modeling of Rack Generated Spur Gears," Mechanism and Machine Theory, Vol. 20 , No. 4, 1985, pp. 351-360.

13. Reddy, S.K., "Rim Effects on Spur Gear Bending Stresses," M.S. Thesis, Univ. of Akron, Akron, OH, 1991.

14. Desalvo, G.J. and Gorman, R.W., ANSYS Engineering Analysis System, User's Manual. Pittsburgh, PA, 1987. 
TABLE I. - GEAR MESH GEOMETRY AND LOADING LOCATION

(a) Gear mesh geometry

\begin{tabular}{|l|r|r|}
\hline & Pinion & Gear \\
\hline Number of teeth & 25 & 50 \\
Pitch radius, in. & 1.25 & 2.50 \\
Base radius, in. & 1.1746 & 2.3492 \\
Addendum radius, in. & 1.35 & 2.60 \\
Dedendum radius, in. & 1.115 & 2.365 \\
\hline Face width, w, in. & 0.625 \\
Pressure angle, $\phi$, deg & 20 \\
Diametral pitch, $\mathrm{P}_{\mathrm{d}}$, in. $^{-1}$ & \multicolumn{2}{|c|}{10} \\
Base pitch, $\mathrm{P}_{b^{\prime}}$ in. & 0.2952 \\
\hline
\end{tabular}

(b) Load and location

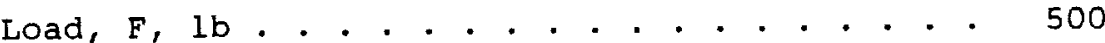

Minimum pinion curvature radius, $u$, in. . . 0.1685

Pinion roll angle to load, $\theta$, deg. . . . 22.62

Pinion pressure angle at load, $\phi_{B}$, deg . . 21.544

Pinion radius to load, $R_{3}$, in. . . . . . . 1.263

TABLE II. - GEAR SEGMENT SIDE REACTIONS

\begin{tabular}{|c|c|c|c|c|c|c|}
\hline \multirow[t]{2}{*}{$\beta$} & \multicolumn{3}{|c|}{ Left end } & \multicolumn{3}{|c|}{ Right end } \\
\hline & $\begin{array}{l}F_{x^{\prime}} \\
1 b\end{array}$ & $\begin{array}{l}F_{y^{\prime}} \\
b_{0}\end{array}$ & $\begin{array}{c}M \\
1 b-i n .\end{array}$ & $\begin{array}{l}F_{x^{\prime}} \\
1 b^{\prime}\end{array}$ & $F_{Y^{\prime}}$ & $\begin{array}{c}M \\
1 b-i n .\end{array}$ \\
\hline 0.45 & -112 & 120 & 4 & 368 & 637 & 31 \\
\hline .72 & -141 & 176 & 18 & 397 & 581 & 40 \\
\hline .98 & -170 & 218 & 34 & 426 & 538 & 51 \\
\hline 1.24 & -195 & 248 & 51 & 451 & 509 & 68 \\
\hline 1.50 & -217 & 267 & 71 & 474 & 490 & 90 \\
\hline 1.76 & -236 & 279 & 93 & 492 & 478 & 116 \\
\hline 2.02 & -249 & 287 & 116 & 505 & 470 & 146 \\
\hline 2.28 & -258 & 291 & 142 & 515 & 465 & 180 \\
\hline 2.55 & -264 & 294 & 168 & 520 & 463 & 216 \\
\hline
\end{tabular}


TABLE III. - LOWEST BACKUP RATIO LIMITS AT WHICH THIN RIM GEAR STRESSES EQUAL SOLID GEAR STRESSES

\begin{tabular}{|c|c|c|c|c|}
\hline $\begin{array}{l}\text { Gear } \\
\text { teeth }\end{array}$ & $\begin{array}{c}\text { Teeth } \\
\text { in } \\
\text { segment }\end{array}$ & $\begin{array}{c}\text { Backup } \\
\text { ratio } \\
\text { curve } \\
\text { knee }\end{array}$ & Model description & Reference \\
\hline------- & --n-- & 1.2 & Appendix design guide & 1 \\
\hline $20,40,80$ & 5 & 1.7 & Photoelastic and finite element & 3,4 \\
\hline 72 & 1 & $\begin{array}{l}{ }^{a} 0.43 \\
b_{1} .7\end{array}$ & Single tooth on a five tooth segment & 5 \\
\hline 30 & 4 & 1.11 & Spoke model with four teeth between spokes & 6 \\
\hline 18 & 1 & $\begin{array}{l}0.43 \\
{ }^{\circ} 0.85\end{array}$ & Rigid support at tooth edge & 7 \\
\hline Rack & $2,6,10$ & $\begin{array}{l}{ }^{a} \\
{ }_{1} .33 \\
{ }_{2} .67\end{array}$ & $\begin{array}{l}\text { Flexible model with simply supported } \\
\text { beam ends }\end{array}$ & 8 \\
\hline 25,50 & 3 & $\begin{array}{l}{ }^{a} 0.67 \\
b_{1} 0.4\end{array}$ & Rigid support at segment edges & 9 \\
\hline 40 & 3 & $\begin{array}{l}{ }^{a} 0.62 \\
b_{0} \\
b_{0}\end{array}$ & Hub support under rim & 10 \\
\hline 25 & 5 & $\begin{array}{l}{ }^{a} 0.7 \\
{ }^{b} \\
1.3\end{array}$ & Rigid support at segment edges & 14 \\
\hline
\end{tabular}

${ }^{\mathrm{a}}$ Tensile.

${ }^{b}$ Compressive.

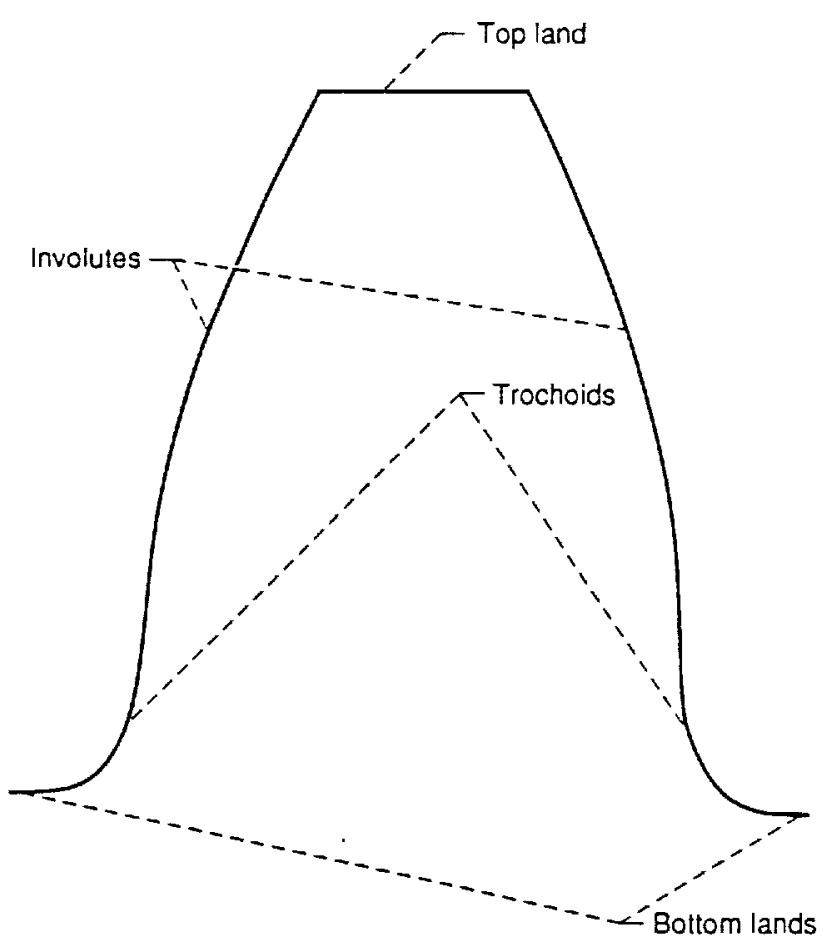

Figure 1.-Gear tooth outline for 25 tooth pinion. 


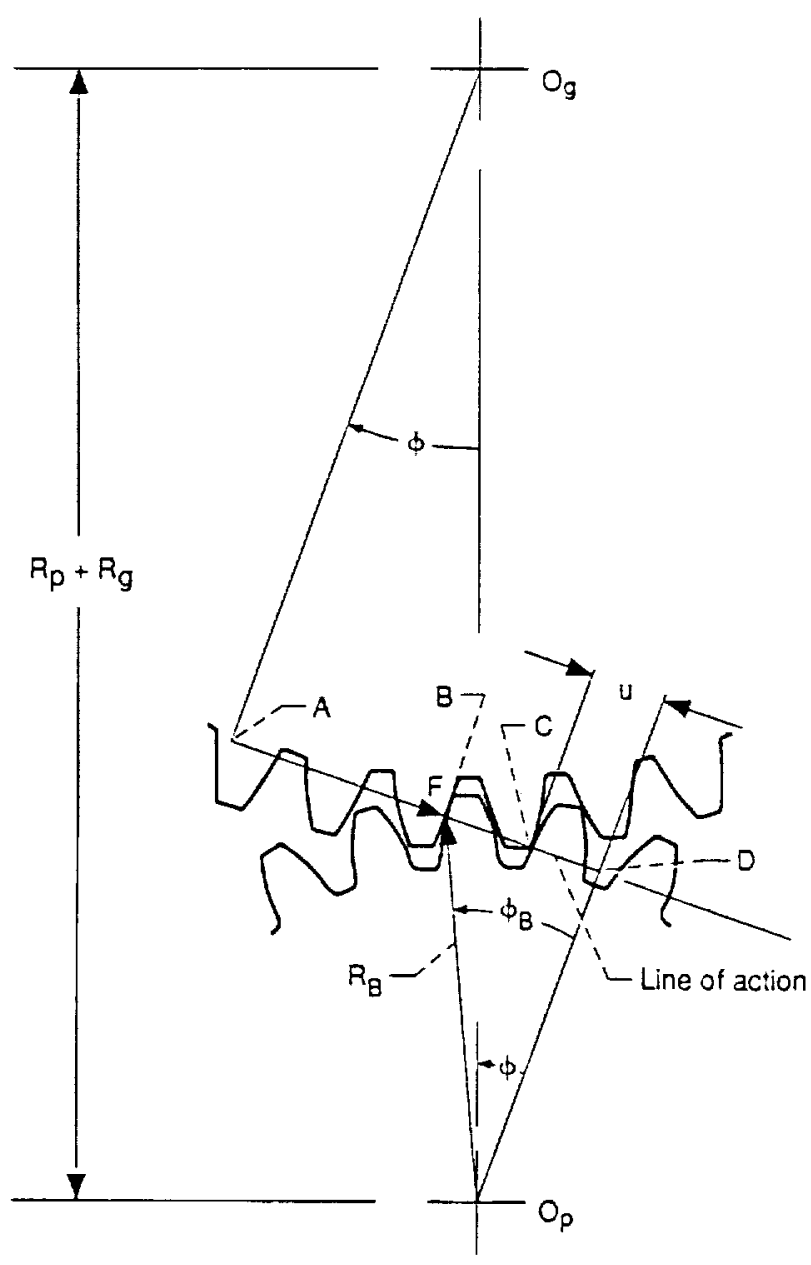

Figure 2.-Highest point of single tooth contact.

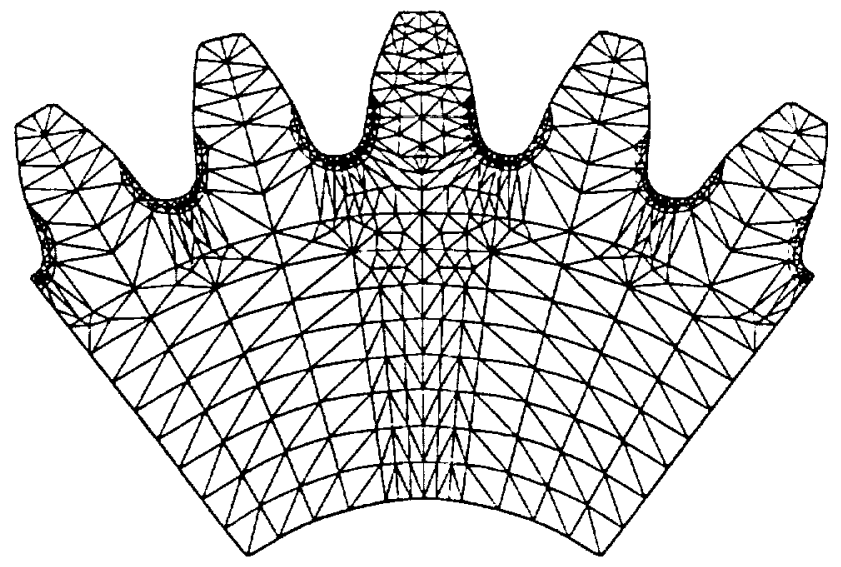

Figure 3.-Five tooth gear segment finite element model.

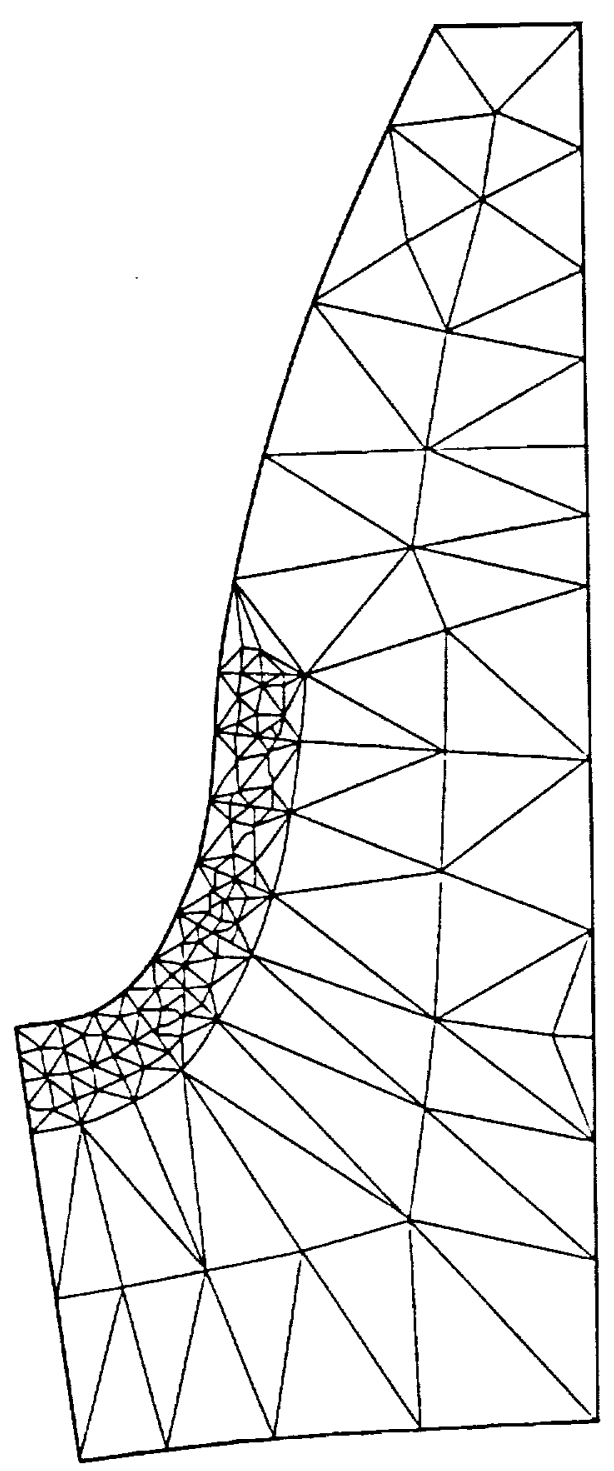

Figure 4.-Left half of central tooth in gear segment finite element model.

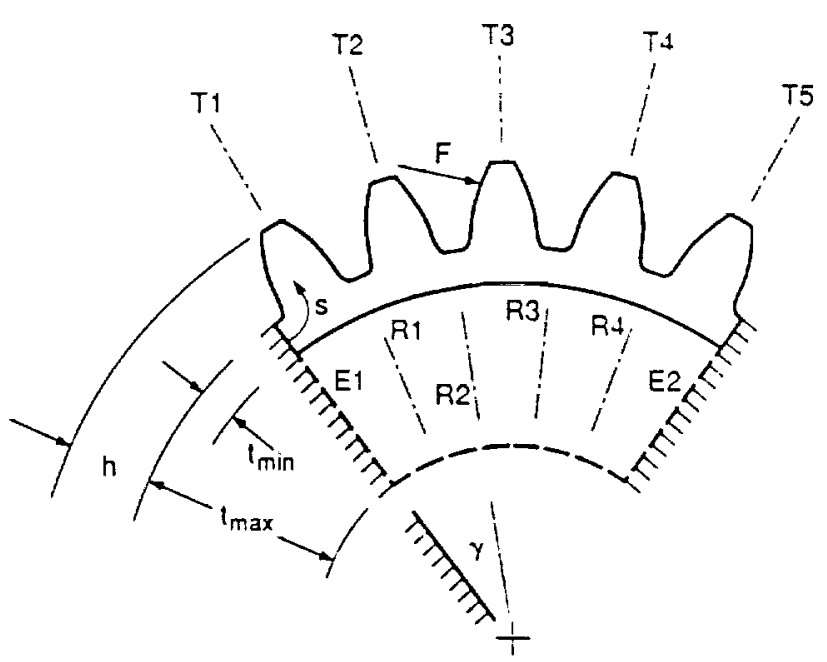

Figure 5.-Loaded five tooth gear segment model showing both thinnest and thickest sections. 


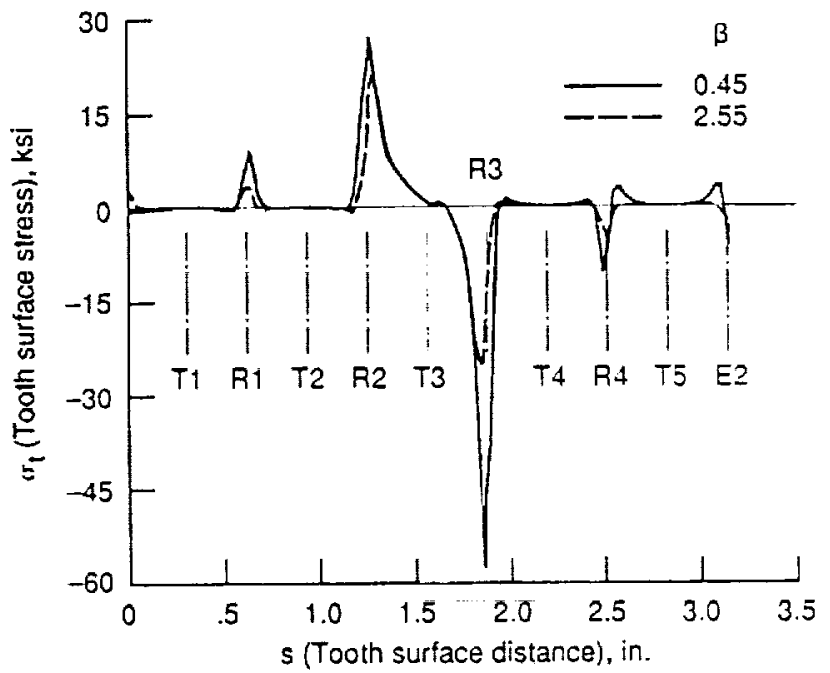

Figure 6.-Tooth surface stresses.

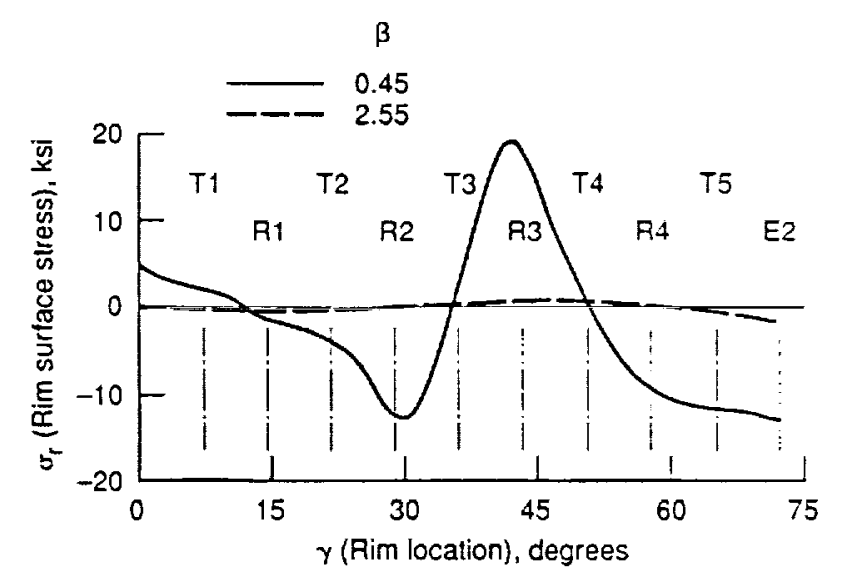

Figure 7.-Rim bottom surface stresses.
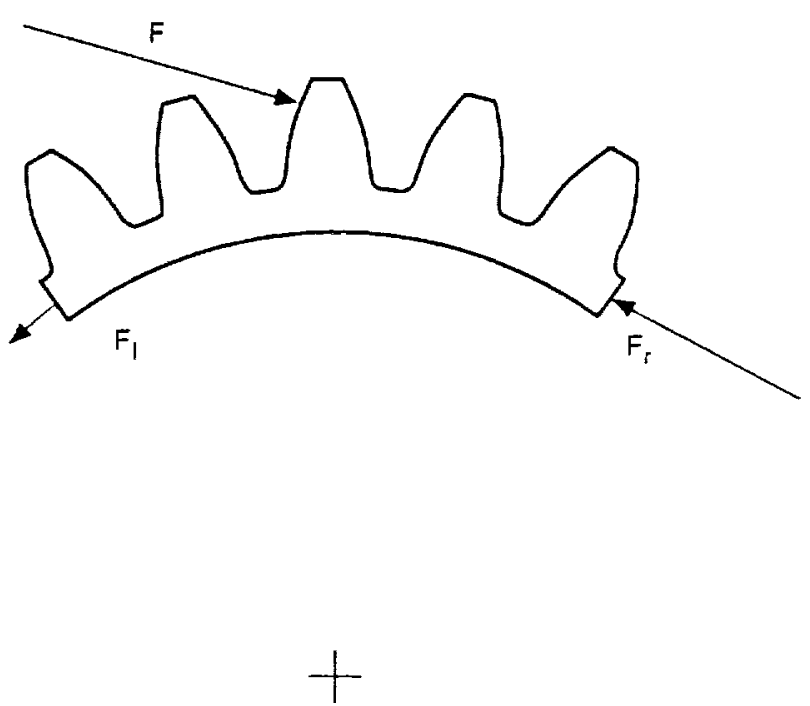

Figure 8.-Support loading for thinnest rim segment model.

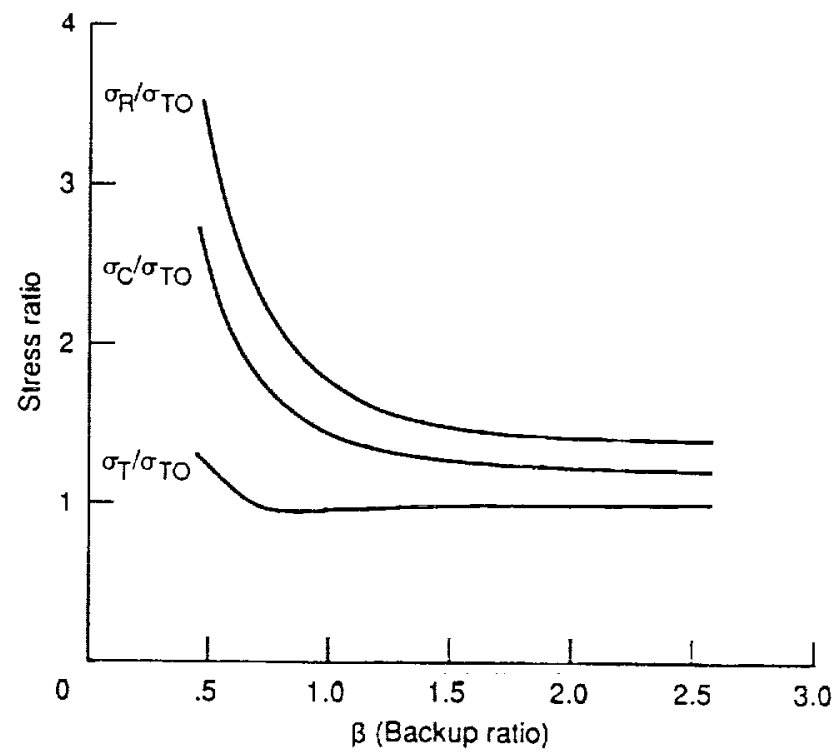

Figure 9.-Maximum tension, compression and range stress ratioed to base tensile stress versus backup ratio. 


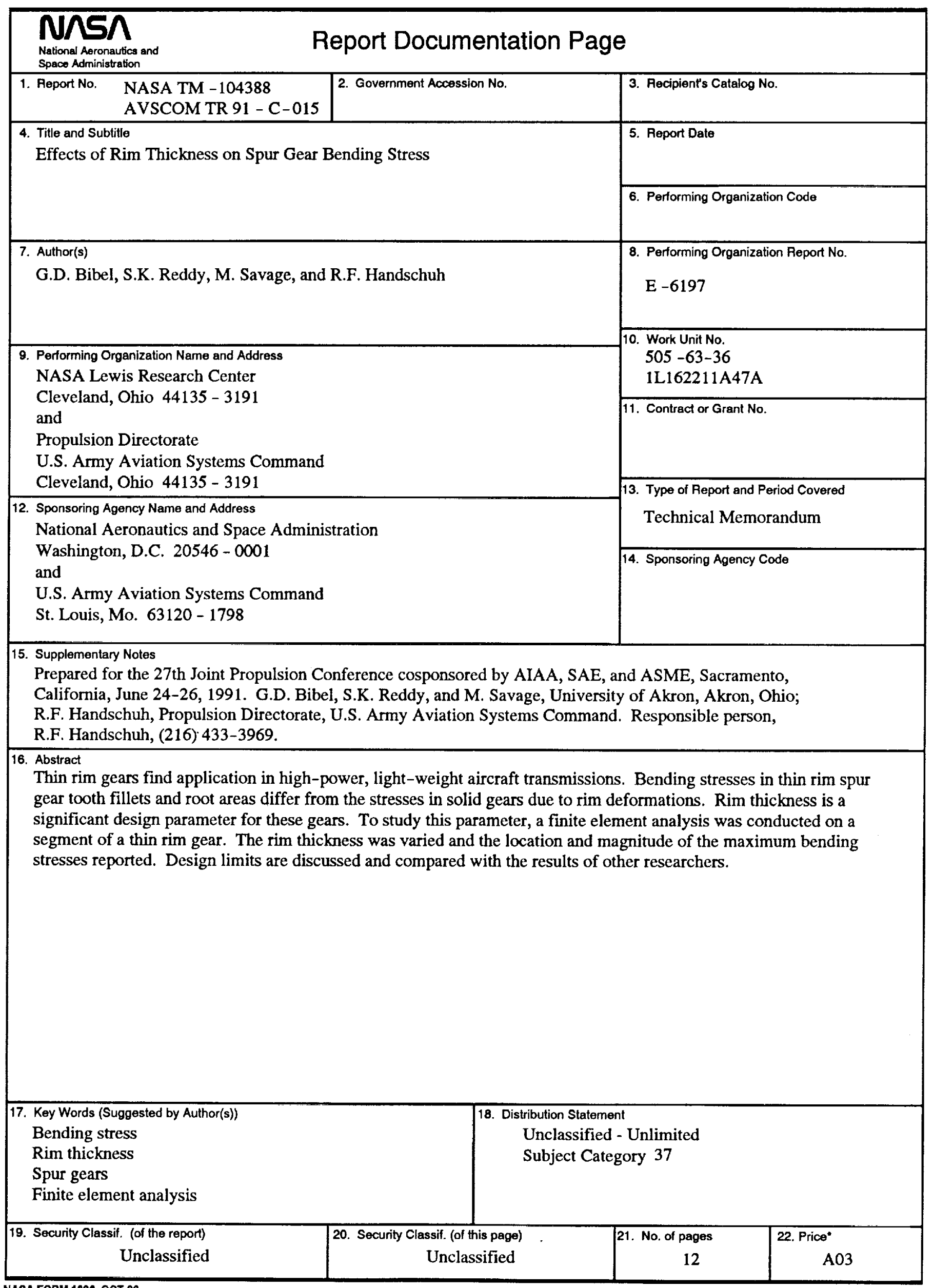


